\title{
GOVERNMENT OF WESTERN NIGERIA
}

Applications are invited for the post of

Medical OfFicer (Leprosy)

in the Western Nigeria Public Service:

\section{Qualifications :}

A medical degree registrable in Nigeria. Experience in the specialty is desirable, but not essential.

\section{Duties :}

The duties of the officer will be those of a Medical Officer (Leprosy) at the Leper Settlement, Ossiomo, near Agbor, Benin Province, Western Nigeria.

\section{Other Conditions of Service:}

On contract for one tour of 12-18 months in the first instance. Salary is between $£ 1,734-£ 2,316$ per annum for a male officer or $£ 1,614-£ 2,196$ per annum for a female officer. A gratuity of E37 10s. 0d. for every completed period of three months satisfactory service. $£ 60$ outfit allowance is payable for salaries below $£ 1,750$ per annum on first appointment. Free first class sea passages or Economy Class Air Passages for officer and family on first appointment and when proceeding on leave. Free medical treatment for officer and his family. Accommodation is provided at low rentals.

\section{Method of Application:}

Applications should be completed in quadruplicate on the prescribed form obtainable from the Official Secretary, (Recruitment Branch), Office of the Agent-General for Western Nigeria, 178/202 Great Portland Street, London, W.1, from whom further particulars may also be obtained.

Candidates living outside the United Kingdom and Western Europe should apply direct to the Secretary, Public Service Commission, Private Mail Bag No. 5005, Ibadan, Nigeria.

\section{Closing Date :}

31 st July 1963. 